\title{
Acetaminophen (Paracetamol) Hepatotoxicity With Regular Intake of Alcohol: Analysis of Instances of Therapeutic Misadventure
}

\author{
Hyman J. Zimmerman ${ }^{1}$ and Willis C. MadDreY ${ }^{2}$
}

\begin{abstract}
Hepatic injury in alcoholics due to intake of acetaminophen (APAP or acetylparaaminophenol) with therapeutic intent has been reported, but the extent of the phenomenon is not clear, pertinent details of the association remain insufficiently clarified, and the importance of the phenomenon is not widely appreciated. The present report describes 67 patients who developed hepatic injury after ingestion of APAP with therapeutic intent. All were regular users of alcohol. Sixty-four percent of the patients were considered to be "alcoholic" or reported intakes greater than $80 \mathrm{~g} / \mathrm{d}, 35 \%$ took $60 \mathrm{~g} / \mathrm{d}$ or less, and the remainder were vague in their reporting. Doses of APAP were in the "nontoxic" range $(<6 \mathrm{~g} / \mathrm{d})$ in $60 \%$ of the group, within the recommended range $(<4 \mathrm{~g} /$ d) in $40 \%$, and at 4.1 to $6 \mathrm{~g} / \mathrm{d}$ in $20 \%$. Characteristic feature was the towering level reached by aspartate transaminase (AST) with figures ranging from 3,000 to 48,000 IU in more than $90 \%$ of cases. Almost $20 \%$ of the patients died. The data on these patients were similar to 94 cases of injury from APAP taken with therapeutic intent reported in the literature. This study provides further evidence of hepatic injury in regular users of alcohol, especially chronic alcoholics, who take APAP with therapeutic intent. Susceptibility is presumably caused by induction of cytochrome P-4502EI by ethanol and by depletion of glutathione (GSH) because of the effects of alcohol, the malnutrition often associated with alcoholism, and the depletion associated with chronic use of APAP and impaired glucuronidation caused by fasting perhaps as well. The syndrome of liver injury is distinctive, marked by uniquely elevated levels of AST, and poses a significant threat. A greater awareness of the phenomenon by the medical and lay community is essential. (HEPATOLOGY 1995;22:767-773.)
\end{abstract}

Abbreviations: APAP, acetaminophen or acetylparaaminophenol; AST, aspartate transaminase; ALT, alanine transaminase; LDH, lactic dehydrogenase; GSH, glutathione; NAC, $N$-acetaminophen.

From ${ }^{1}$ George Washington University and Armed Forces Institute of Pathology, Washington, DC $;{ }^{2}$ University of Texas, Southwestern Medical Center at Dallas, Dallas, TX.

Received January 23, 1995; accepted April 20, 1995

Address reprint requests to: Hyman J. Zimmerman, MD, Professor of Medicine, Emeritus, George Washington University, Distinguished Scientist, Emeritus, Armed Forces Institute of Pathology, Washington, DC 20306-6000.

Copyright $\odot 1995$ by the American Association for the Study of Liver Diseases.

0270-9139/95/2203-0011\$3.00/0
Acetaminophen (APAP) was first synthesized a century ago, but did not enter regular clinical use until the midpoint of this century. In 1955, it was marketed in the United States and in 1960 became an over-thecounter preparation. APAP quickly achieved wide popularity as an effective analgesic, antipyretic agent with, seemingly, hardly any significant adverse effects. However, it soon became apparent that it has hepatotoxic potential, with reports in 1966 of fatal and nonfatal hepatic necrosis produced by suicidal overdose. ${ }^{1,2}$ Taken in suicidal overdose (usually greater than $10 \mathrm{~g}$ ), APAP has led to a large number of cases of severe hepatic necrosis and fatal hepatic failure. ${ }^{3}$ Indeed, this mild, widely used, apparently safe analgesic-antipyretic is also a dose-dependent hepatotoxin. In addition to the large number of cases of fulminant hepatic failure incurred from suicidal attempts, a number of cases have occurred as the result of therapeutic misadventure among alcoholic patients ${ }^{4-39}$ as well as among patients with wasting disease or even brief starvation $^{4,39-41}$ and even a few infants given excessive doses. ${ }^{42-45}$ Almost all of the reported suicidal efforts have involved the ingestion of single large doses, usually in excess of $15 \mathrm{~g}$; although approximately $15 \%$ have taken a dose ranging from 10 to 15 g. ${ }^{3,46}$ Rarely, doses less than $10 \mathrm{~g}$, taken with suicidal intent, have led to liver injury. ${ }^{3,46}$ Doses less than $6 \mathrm{~g}$ per day have been considered nontoxic, and the upper limit recommended for use is $4 \mathrm{~g} / \mathrm{d} .^{3}$ APAP has been considered safer than aspirin as an analgesic for alcoholic patients, in large measure because it is less likely to provoke gastritis. ${ }^{47}$ However, there is considerable evidence that APAP poses a special risk for alcoholic patients as shown by the multiple reports of alcoholic patients who developed severe hepatic injury after taking APAP with therapeutic intent. ${ }^{4-39}$ Despite the large number of these reports, the practicing community seems insufficiently aware of the risk of the drug for patients who consume alcohol on a regular basis, ${ }^{36}$ and some of the current preparations of the drug carry little or no reference to the apparently enhanced susceptibility of alcohol imbibers. A greater awareness of the susceptibility of alcoholic patients seems necessary if effectively sharper focus on the problem is to be achieved. Accordingly, this report describes 67 alcoholic patients or 
TARLE 1. Characteristic of Cases of Hepatic Injury Associated With Therapeutic Use of APAP

\begin{tabular}{|c|c|c|}
\hline Characteristics & Registry & Literature \\
\hline No. of cases & 67 & 94 \\
\hline Male-female ratio & $42 / 25(1.7)$ & $56 / 38(1.5)$ \\
\hline \multicolumn{3}{|l|}{ Age } \\
\hline$<30$ & $7(10 \%)$ & $16(17 \%)$ \\
\hline $30-50$ & $39(58 \%)$ & $52 \quad(54 \%)$ \\
\hline$>50$ & $15(24 \%)$ & $24 \quad(26 \%)$ \\
\hline Unknown & $6(8 \%)$ & $3(3 \%)$ \\
\hline \multicolumn{3}{|l|}{ Doses $(\mathrm{g} / \mathrm{d})$} \\
\hline$<4$ & $27(40 \%)$ & $22 \quad(23 \%)$ \\
\hline $4.1-6$ & $13(20 \%)$ & $25 \quad(27 \%)$ \\
\hline $6.1-10$ & $10 \quad(15 \%)$ & $17 \quad(18 \%)$ \\
\hline $10.1-15$ & $2(3 \%)$ & $1.3(14 \%)$ \\
\hline$>15$ & $5 \quad(7 \%)$ & $5 \quad(5 \%)$ \\
\hline Unclear & $10(15 \%)$ & $13(13 \%)$ \\
\hline \multicolumn{3}{|l|}{ Duration of intake } \\
\hline 1 Day & $7(10 \%)$ & $29(30 \%)$ \\
\hline 1-7 Days & $45 \quad(67 \%)$ & $38 \quad(40 \%)$ \\
\hline 7-30 Days & $4(6 \%)$ & $28 \quad(30 \%)$ \\
\hline$>30$ Days & $8(12 \%)$ & $28 \quad(30 \%)$ \\
\hline \multicolumn{3}{|l|}{ Alcohol intake } \\
\hline "Alcoholic" or "heavy" & $17(25 \%)$ & $55 \quad(60 \%)$ \\
\hline Vague regular use & $8(12 \%)$ & \\
\hline$>80 \mathrm{~g} / \mathrm{d}$ & $18(27 \%)$ & $24 \quad(34 \%)$ \\
\hline$\sim 60 \mathrm{~g} / \mathrm{d}$ & $15(22 \%)$ & $5 \quad(5 \%)$ \\
\hline$<60 \mathrm{~g} / \mathrm{d}$ & $9(13 \%)$ & \\
\hline \multicolumn{3}{|l|}{ Outcome } \\
\hline Death & $13^{*}(18 \%)$ & $19(20 \%)$ \\
\hline Recovered & $52(78 \%)$ & $50(53 \%)$ \\
\hline Unknown & $2 \quad(3 \%)$ & $26(27 \%)$ \\
\hline Zone 3 necrosis & $14 / 16$ & $23 / 26$ \\
\hline
\end{tabular}

* One of the surviving cases who was subjected to transplantation is included with the fatal cases.

other regular users of alcohol who developed hepatic injury after intake of the drug with therapeutic intent and compares them with 94 similar cases reported in the literature.

\section{PATIENTS AND METHODS}

The group analyzed consists of 81 patients reported to a registry* for hepatic injury in alcoholic patients associated with use of APAP (Table 1). All had taken the drug with therapeutic intent. These cases were reported by hepatologists and other colleagues who had been informed of the registry by word of mouth or by letter. Thirty-four physicians submitted single cases, 7 submitted 2 cases, 1 submitted 8 cases, and 1 submitted 17 cases. Thirty-one percent of the cases were from the West Coast, $24 \%$ were from the South (Texas, Tennessee, Louisiana, and Florida), $5 \%$ were from the Midwest, and the remainder were from the East. Fourteen of

* The registry of acetaminophen hepatic injury in alcohol consumers has received support from Whitehall Laboratories. It is part of a registry with broader attention to drug-induced injury that has been maintained by one of the authors (H.J.Z.) and is supported by grants from the Food and Drug Administration (1979 to 1981), Veterans Administration funds (1981 to 1989), Ciby-Geigy Corporation, Basel, Switzerland, and Sandoz. Pharmaceuticals, E Hanover, N.J (1989 to present). the cases were omitted from further analysis because the data were too scanty or unconvincing. The remaining $67 \mathrm{pa}-$ tients are the subject of this study. The characteristics of these patients are compared with those of 94 patients reported in the literature.

The dose or range of dose was stated explicitly in $85 \%$ of the cases. In the remainder, references to the amount of drug were vague, describing some as low, others as high, and others only as therapeutic. Estimates of the amount of alcohol taken regularly were not available in $37 \%$ of the patients who were simply designated "chronic alcoholic" $(25 \%)$ or as regular users without stipulation of the amount (12\%). An additional $27 \%$ reported more than $80 \mathrm{~g} / \mathrm{d}$ of alcohol, and an intake of $60 \mathrm{~g} / \mathrm{d}$ or less of alcohol was reported in $35 \%$ of the patients (Table 1). The estimate of the amount of alcohol taken by patients who provided information was based on the equivalence of $60 \mathrm{~g}$ to four glasses of wine, a "six-pack" of beer, or three ordinary mixed drinks containing hard liquor.

\section{RESULTS}

Age and Gender of Patients. The patients ranged in age from 23 to 88 years. Almost $60 \%$ of the group were between 30 and 50 years old, $10 \%$ were less than 30 , and $24 \%$ were older than 50 (Table 1 ). In $8 \%$ the age was not recorded. Males $(63 \%)$ outnumbered females $(37 \%)$. This distribution is strikingly different from that of the patients taking APAP with suicidal intent, who are mainly young and more often female than male. ${ }^{46}$

Estimated doses of APAP are listed in Table 1. Sixty percent of the patients had taken $6 \mathrm{~g} / \mathrm{d}$ or less of APAP, with $40 \%$ having taken less than $4 \mathrm{~g} / \mathrm{d}$ of APAP. In $15 \%$ of the patients, doses were 6 to $10 \mathrm{~g} / \mathrm{d}$; and in $3 \%$ of the patients, doses were 10 to $15 \mathrm{~g} / \mathrm{d}$. In $7 \%$ of the patients, doses greater than $15 \mathrm{~g} / \mathrm{d}$ had been taken. In 10 patients (15\%) description of the amount taken was vague, and was arbitrarily considered large. The drug had been taken for only 1 day in $10 \%$ of the patients, for 2 to 7 days in $67 \%$, and for periods from weeks to many months in the remainder (Table 1). There was no readily identifiable relationship between daily toxic dose and duration of exposure. Attempts to estimate cumulative doses yielded a wide range with no apparent relationship to hepatic injury.

Also the attempt to correlate recorded dose of APAP with estimated alcohol intake was inhibited by the difficulties in quantitating alcohol intake. Nevertheless, even among the patients who claimed modest alcohol intake (estimated $<60 \mathrm{~g} / \mathrm{d}$ ), five of nine patients reported taking less than $4 \mathrm{~g}$ of APAP daily.

APAP was taken for abdominal pain, headaches, dental pain, back pain, pain of cervical arthritis, acute respiratory illness, systemic infection, or for treatment of "hangover" or pancreatitis (Table 2). In a few instances the drug was administered in the hospital.

The most common clinical manifestations were nausea, vomiting, abdominal distress, or pain. Azotemia of some degree was recorded in $30 \%$ of cases. The available data do not permit distinction between the effects of severe dehydration, hepatic failure, and APAP-induced renal injury. 
TABLE 2. Reported Reasons for Taking APAP

\begin{tabular}{lr}
\hline \multicolumn{1}{c}{ Reasons } & $\%$ \\
\hline "Flu" or fever* & 19 \\
Hangover & 6 \\
Pain & 55 \\
Abdomen & 21 \\
Back & 4 \\
Dental & 4 \\
Headache & 6 \\
Joint & 10 \\
Mouth carcinoma & 1 \\
"Pain" vague & 9 \\
Unclear & 20 \\
\hline
\end{tabular}

* Includes upper respiratory infection and related syndromes.

Laboratory Values. All of the patients had abnormal laboratory values on admission. The most important clinical-biochemical characteristic is the high and often towering level of aminotransferase. Values for aspartate transaminase (AST) exceeded 1,000 IU in 97\% of the patients, and 3,000 IU in more than $90 \%$ of them; many were much higher (Fig. 1). Indeed, more than half of the patients had AST values greater than 5,000 IU, many had values greater than $10,000 \mathrm{IU}$, and some greater than 20,000 IU. One patient had an AST value of 48,000 IU. Comparison with the values of alcoholinduced hepatitis and viral hepatitis is shown in Fig. 1. Initial values for alanine transaminase (ALT) were lower than those for AST in 84\% of patients in whom both enzymes were measured, with AST:ALT ratios ranging from 1.2 to 25 . In the other $16 \%$ of patients, the two values were approximately equal or the ALT value exceeded the AST value. Levels of AST decreased rapidly, usually decreasing by as much as 50\% during the first 24 hours in the hospital (in the cases where serial enzymes were available). Values for lactic dehydrogenase ( $\mathrm{LDH}$ ) also were extraordinarily high in many of the cases, but LDH levels were not as consistently high nor as regularly determined as those of the AST.

Blood levels of APAP were available in 32 cases. In 18 cases the level ranged from 0 to $10 \mathrm{mg} / \mathrm{L}$. In the remainder, values ranged from 13 to $97 \mu \mathrm{g} / \mathrm{mL}$.

The histological character of the hepatic injury was available in 15 patients: 5 were autopsy sections, 9 were biopsy specimens, and 1 was a liver recovered at transplantation. One case showed massive necrosis, and 13 showed zonal (zone 3 or zones 3 and 2 ) necrosis. One showed minor evidence of necrosis.

Death caused by liver failure occurred in $18 \%$ of the patients reported to the registry (Table 1). (One patient who underwent transplantation and survived is included with the "fatal" cases.) This figure is comparable to the $20 \%$ figure cited in the analysis of 25 cases by Seeff et al. ${ }^{25}$ For $5 \%$ of the patients, the outcome was not reported.

Treatment included $N$-acetylcysteine in 25 patients, 24 among the surviving cases and 1 among the fatal cases.

\section{DISCUSSION}

The 67 cases described in this report are similar to the 94 cases reported in the literature (Table 1). Sex and age distribution are similar, as are doses, duration of intake of APAP, and outcome. Indeed, the similarities permit discussion of these 161 cases as a group.

The syndrome of APAP-induced hepatic injury in alcoholic patients is clearly a distinctive one. Indeed, it has become a classic syndrome of medicine. The towering levels of AST, usually accompanied by a lower level of ALT, provide a virtually pathognomonic marker. The zone 3 necrosis is a classical hepatoxic lesion and the fatal outcome in almost one fifth of the patients marks its gravity.

These aminotransferase values are strikingly different from those characteristically found in alcoholic hep-

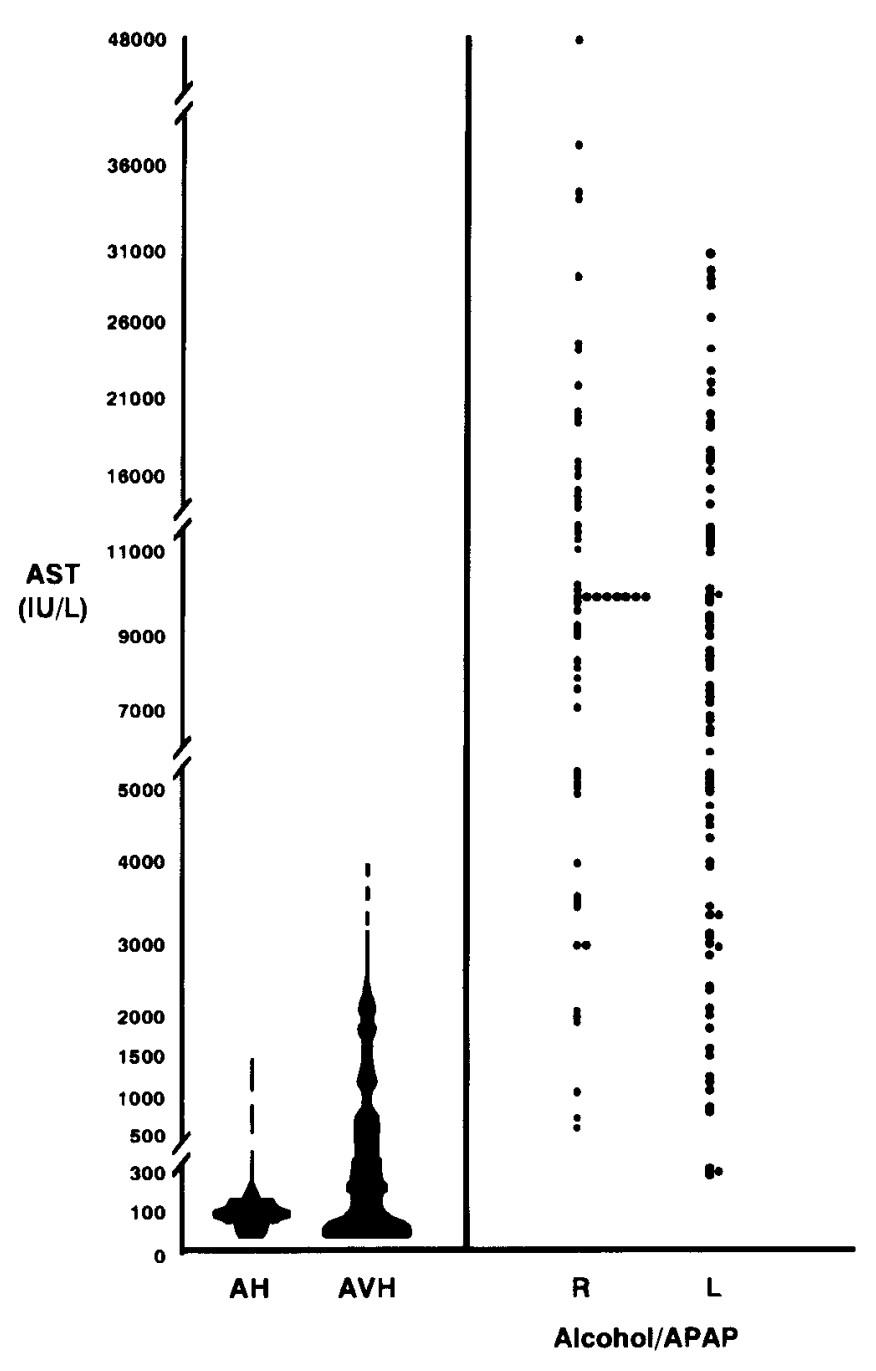

Fig. 1. Values for AST in 161 regular users of alcohol who had ingested APAP with therapeutic intent, 67 from the registry, and 94 from the literature. Values for 175 patients with alcohol-induced hepatitis and 347 patients with viral hepatitis from previously published studies. ${ }^{48,49}$ Abbreviations: $\mathrm{AH}$, alcoholic hepatitis; AVH, acute viral hepatitis; $R$, alcohol/APAP hepatotoxicity registry cases; $L$, alcohol/APAP hepatotoxicity literature cases. 
atitis where AST levels rarely exceed $250 \mathrm{IU}$ (Fig. 1). ${ }^{48}$ The AST levels in more than $90 \%$ of the patients with APAP toxicity also are higher than those usually observed in viral hepatitis, where the AST levels range from 200 to $3,000 \mathrm{IU}$, and in most cases are much less than 3,000 or even $2,000^{49}$ (Fig. 1). AST values greater than 3,000 IU occur in only approximately $1 \%$ of patients with acute viral hepatitis, ${ }^{49}$ in sharp contrast to the AST levels found in the 161 cases, in whom the vast majority had values ranging from 3,000 to 48,000 $U$. There can be no doubt that this enzymologic marker is characteristic and indeed distinctive for the toxic injury of APAP. Only in other toxic injury are such high AST values observed. ${ }^{50}$ Instances of $\mathrm{CCl}_{4}{ }^{51}$ and chloroform $^{52}$ poisoning, often in an alcoholic patient, can lead to values of AST of 25,000 to 30,000 units. $^{9}$ However, acute carbon tetrachloride and chloroform poisoning is so rare that values in the range noted in this report are virtually pathognomonic of APAP toxicity.

Also characteristic of the APAP injury is zone 3 necrosis observed in all but 2 of the 15 patients whose histology was available and in 23 of the 26 cases reported in the literature (Table 1). Zone 3 necrosis is a classical hepatotoxic lesion. ${ }^{53}$ That zone is the area of greatest concentration of the cytochrome $\mathrm{P}-450$ system and, therefore, the site of maximal production of the active metabolite of APAP. ${ }^{54,55}$

Of particular importance is the occurrence of APAPinduced hepatic injury as a therapeutic misadventure. Indeed, a majority of the patients reported taking doses well below the accepted toxic range. Half of the patients in the literature and $60 \%$ of those in the registry had taken $6 \mathrm{~g}$ or less per day, a level generally accepted as nontoxic; and $23 \%$ and $40 \%$ of the respective groups had taken less than $4 \mathrm{~g} / \mathrm{d}$, the recommended safe upper limit of dose for adults (Table 1). Only 18 of the published patients had taken more than $10 \mathrm{~g} / \mathrm{d}, 9$ of them in the recent report by Whitcomb and Block. ${ }^{41}$ The reliability of these doses is subject to the concern that they were reported by patients and those close to the patients and may have been understated or overstated. Nevertheless, the similar distribution of doses found in the analysis of 9. - cases reported in the literature and of the 67 reported to our registry (Table 1) as well as in a small group of cases in $1986^{25}$ provides validity for the figures.

The presumed basis for the potentiation of APAP hepatotoxicity by ethanol, based on the knowledge of the metabolism of the drug by the liver, has been amply discussed. ${ }^{55-59}$ Elegant studies performed in the early $1970 \mathrm{~s}^{54,55}$ established that APAP, taken in therapeutic doses, is metabolized in the liver through two pathways (Fig. 2). Most of the drug (80\% to 90\%) is conjugated with glucuronic acid or sulfate yielding the nontoxic conjugates that are excreted by the kidney. A small proportion $(\sim 5 \%)$ is metabolized by the cytochrome $\mathrm{P}$ 450 system to a reactive electrophilic intermediate. This metabolite is rendered nontoxic by conjugation with glutathione (GSH) to form mercapturic acid and related conjugates that also are excreted in the urine. If the drug is taken in excessive doses, an augmented amount is converted by cytochrome P-450 to the highly reactive, toxic intermediate metabolite.$^{54,55}$ It then may reach a level that overwhelms the protective mechanism of GSH conjugation and ultimately, through covalent binding to hepatocyte proteins or other injurious effects of active metabolites (oxidative stress), leads to hepatocellular necrosis. ${ }^{53-59}$ Factors that enhance the toxicity of APAP include increased production of active metabolites, decreased stores of $\mathrm{GSH}^{53}$ and, of course, increased amounts of drug (Fig. 2), and, perhaps, impaired glucuronidation. ${ }^{4}$

Therapeutic doses of APAP have the apparent potential of producing liver damage if they are associated with circumstances that enhance the activity of the P-450 system leading to increased production of toxic metabolite or that interfere with the protective mechanism by depleting available GSH. Intake of alcohol can do both. ${ }^{56-59}$ Ethanol is an inducer of the cytochrome P450 system, ${ }^{60-70}$ particularly of $\mathrm{P}-4502 \mathrm{E} 1$; ethanol and APAP are both metabolized by P-4502E $1 .{ }^{60}$ It is P$4502 \mathrm{E} 1$ that is mainly responsible for the conversion of APAP to its active metabolite. ${ }^{60-62}$ There is convincing evidence for the $\mathrm{P}-450$ induction in rodents, ${ }^{62-64}$ rabbits, ${ }^{60,61}$ and nonhuman primates, ${ }^{66}$ and controversial $^{71-74}$ evidence for it in humans. ${ }^{65-70}$ Alcohol intake also appears to deplete GSH by inhibiting its synthe$\operatorname{sis}^{73}$ and, in the alcoholic patient, by the malnutrition that results from the alcoholism-associated life style. ${ }^{62}$ Also GSH depletion is presumably enhanced by the intake of APAP for days, weeks, or even months in many patients because APAP removes GSH by its metabolism. ${ }^{73}$ In any event, whether caused by GSH depletion, enzyme induction, or both, enhancement of APAP-induced hepatic injury by alcohol has been shown in experimental animals ${ }^{62,63,74,75}$ and has been apparent among patients taking overdoses of APAP with suicidal intent ${ }^{76-78}$ as well as in the many reported instances of hepatic injury provoked by doses below the accepted toxic levels described in this and other summaries. $^{2 \tilde{n}, 37}$

The report by Whitcomb and Block ${ }^{41}$ of 21 patients who developed hepatic injury after intake of APAP with therapeutic intent has focused on the role of fasting in enhancing the hepatotoxic effects of APAP. These investigators found that recent fasting seemed more important than recent alcohol use among the patients whose dose was modest ( 4 to $10 \mathrm{~g}$ ). They suggest that fasting, by depleting hepatic carbohydrate reserves, prevents adequate glucuronidation and shunts APAP metabolism from glucuronidation to microsomal oxidation, thus decreasing conjugation (detoxification) and enhancing conversion of APAP to the toxic metabolite (toxification). ${ }^{41}$ Whereas chronic alcohol consumption per se does not appear to alter glucuronidation, malnutrition associated with the life style of alcohol abuse could add impaired glucuronidation to the toxicity enhancement of P-4502E1 induction and GSH depletion.

Treatment with $N$-acetaminophen (NAC) that has 
Fig. 2. Scheme of effects of alcohol on APAP metabolism and toxicity. Alcohol may lead to increased dose, increased activation, and decreased GSH stores, leading to decreased detoxification and resulting in increased covalent binding to key proteins and to necrosis. Impairment of glucuronidation by glycogen depletion caused by fasting would enhance toxicity by diverting more metabolism along the toxifying pathway (P4502E1). (Modified and reprinted with permission from Zimmerman. ${ }^{55}$ )
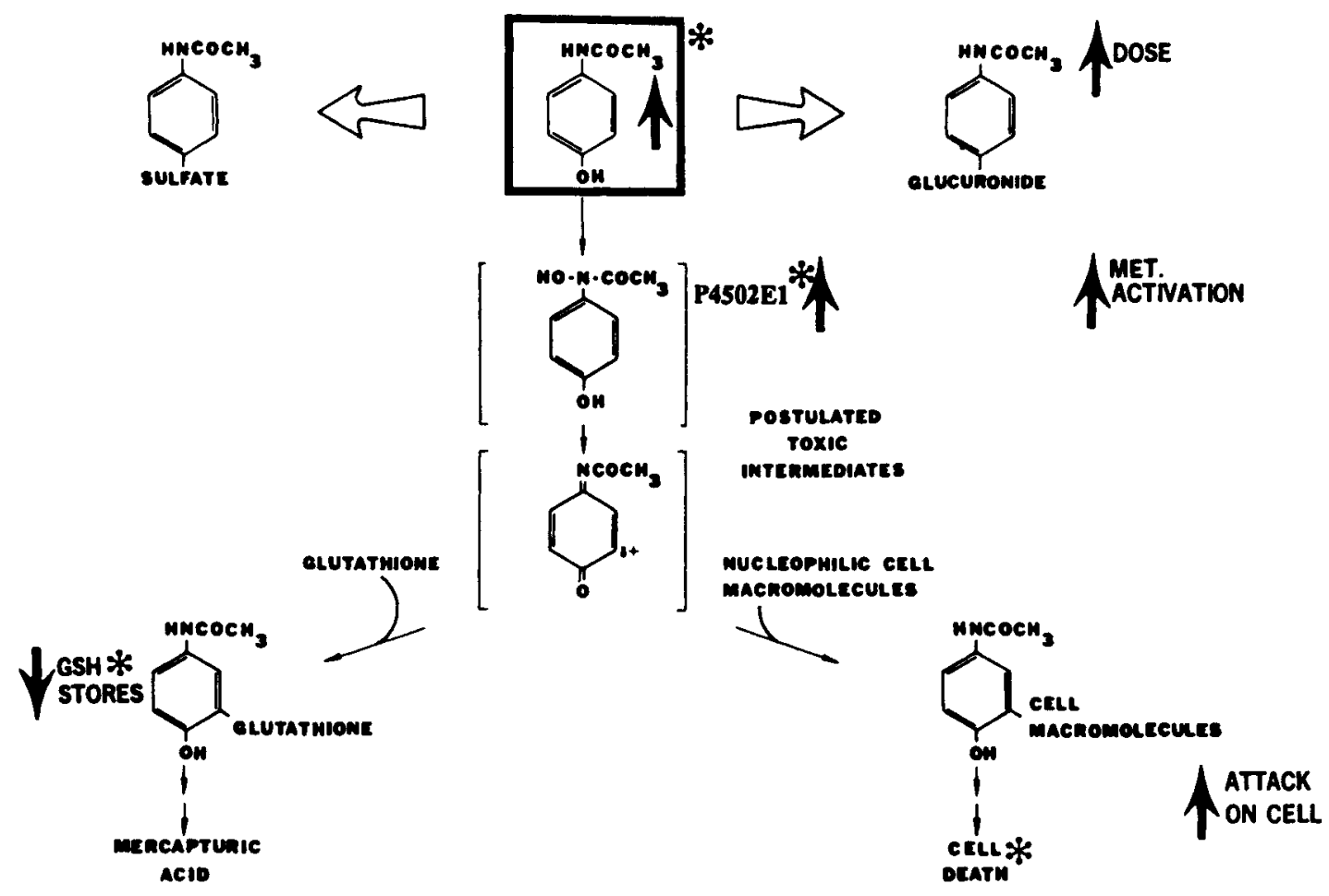

Pathways of acetaminophen disposition. been very successful in preventing or ameliorating hepatic injury after acute, suicidally motivated intake of APAP may be judged to have little place in the syndrome of APAP injury as a therapeutic misadventure. The association with APAP is recognized only after the hepatic injury has evolved and the treatment with NAC by then would presumably have little benefit. However, there are no data bearing on the issue.

Alcohol can not only enhance the toxicity of APAP, it also can protect against it. ${ }^{77,78}$ The effect depends on the time of administration of the ethanol. Chronic administration of alcohol to experimental animals increases the hepatotoxic effects of APAP, a phenomenon attributed to the already cited enhanced production of reactive metabolite by $\mathrm{P}-4502 \mathrm{E} 1$ and to depletion of GSH. In contrast, the acute administration of ethanol, close to the intake of APAP, has been shown to have a short-term protective effect. ${ }^{81,82}$ Presumably, this is caused by its ability to decrease the production of reactive metabolites from APAP by competing for the P450 , by inhibiting nicotinamide adenine dinucleotide phosphate-dependent covalent binding of reactive metabolites, and perhaps by other effects. ${ }^{77-80}$

Data on the amount of alcohol required to enhance the toxicity of APAP in humans are not available. Almost all of the 161 patients (Table 1) drank regularly and to excess; but $35 \%$ of the registry cases claimed to have taken relatively small amounts of ethanol $(\leq 60$ $\mathrm{g} / \mathrm{d})$. However, adequate data on amounts of alcohol, duration of intake, or interval between intake of alcohol and intake of APAP are not available. Recent studies suggest that the induction of $\mathrm{P}-450$ by ethanol subsides by 5 days after withdrawal of the alcohol. ${ }^{65}$

The incidence of APAP-induced injury as a therapeutic misadventure in the alcoholic patient is not clear. The 67 cases in this report and the 94 cases in the literature show that the problem is real and of some importance. Indeed the recent review of liver failure by Lee ${ }^{83}$ suggests that APAP toxicity, among alcoholics or binge drinkers, may be the most frequent single cause of liver failure in the United States at this time. Nevertheless, the number of cases recorded is relatively small, considering the widespread use of APAP and the high frequency of intake of alcohol in excess. However, it is our impression that there is considerable underreporting of the syndrome because it is insufficiently appreciated by practicing physicians. Also, there may be constitutional differences in susceptibility among individuals with equal degrees of GSH depletion and ethanol induction.

Both physicians and the nonmedical users of APAP should be aware of the enhancement of susceptibility by alcohol intake. The occurrence of hepatic injury as a therapeutic misadventure is convincing and the adverse effect even of doses in the recommended range $(<4 \mathrm{~g})$ in some patients is also credible. It is our view that individuals who take more than $60 \mathrm{~g} / \mathrm{d}$ of alcohol should take no more than $2 \mathrm{~g} / \mathrm{d}$ of APAP.

The acceptedly safe level of some of the doses taken that had produced hepatic injury does not, however, speak adequately to the risk of the drug for the alcoholic. The intake, by the alcoholic patient with thera- 
peutic intent, of larger than "safe" doses reflects ignorance of the potential for hepatotoxicity of APAP as well as carelessness. A clear exposition of the hazard of APAP for alcoholic patients would presumably lead to more care and less toxicity.

In summary, APAP is a classic hepatotoxin in large doses and an important one when the toxicity of therapeutic doses is enhanced by alcoholism. The enhancement by alcoholism presumably depends on the induction of P-4502E1, depletion of GSH, perhaps fasting, and probably individual factors. A more adequate awareness of the problem by physicians and potential users of the drug is needed.

Acknowledgment: We are grateful to Norine Spencer for her assistance in the preparing the manuscript and the following physicians who submitted cases to the registry: Drs H. R. Almond, Richmond, VA; J. Balint, Albany Medical College, Albany, NY; D. Barrett, Salem, VA; B. Barney, Dallas, TX; K. Benner, Oregon Health Sciences University, OR; J. L. Boyer, Yale University School of Medicine; R. Burk, Vanderbilt University; S. H. Caldwell, Charlottesville, VA; J. Cuthbert, University of Texas Southwestern Medical Center; S. Danovitch, Washington, DC; T. Deas, Forth Worth, TX; S. J. Drewniak, Boston, MA; H. Fromm, George Washington University, Washington, DC; N. Greenberger, University of Kansas Medical Center, KS; B. Hodges, University of Texas Southwestern Medical Center, Dallas, TX; B. Horton, University of Texas Southwestern Medical Center, Dallas, TX; L. J. Jeffers, University of Miami, Miami, FL; W. F. Jones, University of Texas Southwestern Medical Center, Dallas, TX; D. Langdon, HCA South Arlington Medical Center, Arlington, TX; D. Levinson, George Washington University, Washington, DC; D. Pham, Washington, DC; J. Longacher, Richmond, VA; C. Y. Manzarbeitia, Virginia Transplant Service, Falls Church, VA; Uma Murthy, VA Medical Center, Syracuse, NY; T. B. Reynolds, University of Southern California; K. Romito, Olympia, WA; S. Schenker, University of Texas San Antonio, San Antonio, TX; E. Schiff, University of Miami, Miami, FL; L. B. Seeff, VA Medical Center, Washington, DC; L. Stein, Temple University, Philadelphia, PA; J. M. Stormont, University of Rochester, Rochester, NY; C. Tamburro, University of Kentucky, KY; A. Tatar, Chicago, IL; R. T. Whitlock, New York, NY; D. Yee, Wichita, KS.

\section{REFERENCES}

1. Davidson DGD, Eastham WN. Acute liver necrosis following overdoses of paracetamol. Br Med J 1966;2:497-499.

2. Thomas JS, Prescott LF. Liver damage and impaired glucose tolerance after paracetamol overdoses. Br Med J 1966;2:506507.

3. Black M. Acetaminophen hepatotoxicity. Ann Rev Med 1984; 35:577-593.

4. Barker JD Jr, De Carle DJ, Anuras S. Chronic excessive acetaminophen use and liver damage. Ann Intern Med 1977;87:299. 301.

5. Emby DJ, Fraser BN. Hepatotoxicity of paracetamol enhanced by ingestion of alcohol. Reports of 2 cases. S Afr Med J 1977;51:208-209.
6. Vilstrup V, Henningsen NC, Hansen IF. Liver damage after paracetamol. Ugeskr Laeg 1977; 139:831-834

7. Goldfinger R, Ahmed KS, Pitchssoni CS, Weseley SA. Concomitant alcohol and drug abuse enhancing acetaminophen toxicity Am J Gastroenterol 1978; 70:385-388.

8. Gerber MA, Kaufmann H, Klion F, Alpert LI. Acetaminophen associated hepatic injury. Report of two cases showing unusual portal tract reactions. Hum Pathol 1980;11:37-42.

9. LaBreque DR, Mitros FA. Increased hepatotoxicity of acetaminophen in the alcoholic. Gastroenterology 1980;78:1310.

10. Licht H, Seeff LB, Zimmerman HJ. Apparent potential of acetaminophen toxicity by alcohol. Ann Intern Med 1980;92:511.

11. McClain CJ, Kromhaut JP, Peterson FJ, Holtzman JL. Potentiation of acetaminophen toxicity by alcohol. JAMA $1980 ; 244: 251$. 253.

12. Johnson MW, Friedman PA, Mitch WE. Alcoholism, non-prescription drug and hepatotoxicity. The risk from unknown acetaminophen ingestion. Am J Gastroenterol 1981;76:530-533

13. Black M, Cornell JF, Rabin L, Schachter N. Late presentation of acetaminophen hepatotoxicity. Dig Dis Sci 1982;27:370-374.

14. Davis AM, Helms CM, Mitrosis FA, Yong YM, LaBrecque DR Severe hepatic damage after acetaminophen use in psittacosis. Am J Med 1983;74:349-352

15. Levinson M. Ulcer, back pain and jaundice in an alcoholic. Hosp Pract $1983 ; 18: 48$ N-48S.

16. Erickson RA, Runyan BA. Acetaminophen hepatotoxicity associated with alcoholic pancreatitis |Correspondencel. Arch Intern Med 1984;144:1509-1510.

17. Himmelstein DU, Woolhandler SJ, Adler RO. Elevated SGOT/ SGPT ratio in alcoholic patients with acetaminophen toxicity. Am J Gastroenterol 1984;79:718-720.

18. Stolt CM, Johnson SA. Terapeutiskt paracetammolinting orsakade akut jurunsufficicans och liver parerken. Lakartidningen 1984;81:1313.

19. Fleckenstein JL. Nyquil and acute hepatic necrosis [Correspondencej. N Engl J Med 1985;313:48.

20. Kaysen GA, Pond SM, Roper MH, Menke DJ, Marrama MA. Combined hepatic and renal injury in alcoholics during therapeutic of acetaminophen. Arch Intern Med 1985; 145:2019-2023.

21. Leist MH, Gluskin LE, Payne JA. Enhanced toxicity of acetaminophen in alcoholics. Report of three cases. J Clin Gastroenterol $1985 ; 7: 55-59$.

22. Kartsonis A, Reddy KR, Schiff ER. Alcoholic, acetaminophen and hepatic necrosis /Correspondencel. Ann Intern Med 1986; 105:138-139

23. Lesser PB, Vietti MM, Clark WD. Ethanol enhancement of therapeutic doses of acetaminophen by alcohol. Dig Dis Sci 1986;31:103-105.

24. O'Dell JR, Zetterman RK, Burnett DA. Centrilobular hepatic fibrosis following acetaminophen-induced hepatic necrosis in an alcoholic. JAMA 1986;255:2636-2637.

25. Seeff LB, Cuccherini BA, Zimmerman HJ, Adler E, Benjamin SB. Acetaminophen toxicity in alcoholic. A therapeutic misadventure. Ann Intern Med 1986; 104:399-404.

26. Bell $\mathrm{H}$, Schonsby $\mathrm{H}$, Raknervd $\mathrm{N}$. Severe liver damage after therapeutic doses of paracetamol. Tidsakr Nor Laegeforen 1987; 107:1037-1040.

27. Bidault I, Lagier G, Garnier R, Pallot JL, Larrey D. Les hepatitis par toxicite subaigue du paracetaol existent elles? A propos de 3 cas eventuals. Therapie 1987;42:387-388.

28. Denison H, Kaczynski J, Walkerstedt S. Paracetamol medication and alcohol abuse: a dangerous combination for the liver and kidney. Scand J Gastroenterol 1987;22:701-704

29. Floren C-H, Thesleff P, Nilsson A. Severe liver damage caused by therapeutic doses of acetaminophen. Acta Med Scand 1987;222:285-288.

30. Luquel L, Azzi R, DeSaint B, Massart JD, Offenstadt G. Hepatonephritic aigue chez l'alcoolique apres prise de paracetamol a dop therapeutic. Presse Med 1988;17:1318.

31. Pezzano M, Richard C, Lampl E, Pellitier G, Fabré M, Rimailho A, Auzepy P. Toxicité hepatique et renate de paracetamol chez I alcoolique chronique. Presse Med 1988;17:21-24. 
32. Keaton MR. Acute renal failure in alcoholic during therapeutic acetaminophen digestion. South Med J 1988;81:1163-1166.

33. Baeg N-J, Bodenheimer HC Jr, Burchard K. Long term sequelae of acetaminophen associated fulminant hepatic failure. Relevance of early histology. Am J Gastroenterol 1988;83:569-571.

34. Foust RT, Reddy KR, Jeffers LJ, Schiff ER. Nyquil-associated liver injury. Am J Gastroenterol 1989;84:422-425.

35. Wooten FT, Lee WM. Acetaminophen hepatotoxicity in the alcoholic. South Med J 1990;83:1047-1049.

36. Kumar S, Rex DK. Failure of physicians to recognize acetaminophen hepatotoxicity in alcoholics. Arch Intern Med 1991; 151:1189-1191

37. McClain C.J, Holzman J, Allen J, Kromhout J, Shedlofsky S. Clinical features of acetaminophen toxicity. J Clin Gastroenterol 1988; 10:76-80.

38. Edwards R, Oliphant J. Paracetamol toxicity in chronic alcohol abusers - a plea for greater consumer awareness. N Z Med J 1992; 105:174-175.

39. Eriksson LS, Broome U, Kalin M, Lindlhom M. Hepatotoxicity due to repeated intake of low doses of paracetamol. J Intern Med 1992;231:567-570.

40. Ware AJ, Upchurch KS, Figenbrodt EH, Norman DA. Acetaminophen and the liver [Correspondence]. Ann Liver Med 1978; $88: 267-268$

41. Whitcomb DC, Block GD. Association of acetaminophen hepatotoxicity with fasting and ethanol use. JAMA 1994;272:1845.

42. Agran PF, Zenk KE, Romansky S. Acute liver failure and encephalopathy in a 15 month old infant. Am J Dis Child 1983; 137:1107-1114

43. Clark JH, Russel GJ, Fitzgerald JF. Fatal hepatotoxicity in a 2 year old. J Indian S Med Assoc 1983;76:832-835.

44. Swetnam SM, Florman AL. Probable acetaminophen toxicity in an 18 month old infant due to repeated over dosing. Clin Pediatr (Phila) 1984;23:104-105.

45. Smith DW, Ishakson G, Frankel LR, Kerner JA Jr. Hepatic failure following ingestion of multiple doses of acetaminophen in a young child. J Pediatr Gastroenterol Nutr 1986;5:822-825.

46. Hamlyn AN, Douglas AP, James O. The spectrum of paracetamol (acetaminophen) overdosage: clinical and epidemiological studies. Post Grad Med J 1978;59:400-404.

47. Harkinson RD. Acetaminophen as an aspirin substitute. Clin Depend 1980;4:71-84.

48. Harinasuta U, Chomet B, Ishak KG, Zimmerman HJ. Steatonecrosis-Mallory body type. Medicine 1967;64:141-162.

49. Rozen P, Korn RJ, Zimmerman HJ. Computer analysis of liver function tests and their interrelationship in 347 cases of viral hepatitis. Isr J Med Sci 1970;6:67-79.

50. Zimmerman H.J, Seeff LB. Serum enzymes in liver disease. In: Eugene L. Coodley, ed. Diagnostic enzymology. Philadelphia: Lea \& Febiger, 1970:1-38.

51. Wroblewiski F. Clinical significant of alterations in transaminase activities in serum and other body fluids. Adv Clin Chem 1958; 1:313-340.

52. Litovitz TL, Schmitz BT, Matyrine N, Martin TG. Report of American Association of Poison Control Centers. National Data Collection System. Am J Emerg Med 1988;6:479-520.

53. Mitchell JR, Jollow DJ, Potter WZ, Gillette JR, Brodie BB. Acetaminophen-induced hepatic necrosis: IV Protective role of glutathione. J Pharmacol Exp Ther 1973;187:211-217.

54. Jollow DJ, Mitchell JR, Potter WZ, Davis DC, Gillette JR, Brodie BB. Acetaminophen-induced hepatic necrosis II. Role of covalent binding in vivo. J Pharmacol Exp Ther 1973; 187:195-202.

55. Zimmerman HJ. Hepatotoxicity: adverse effects of drugs and other chemicals on the liver. New York: Appleton-CenturyCrofts, 1978.

56. Zimmerman HJ. Effects of alcohol on other hepatotoxins. Alcohol Clin Exp Res 1986;1:3-15.

57. Maddrey WC. Hepatic effects of acetaminophen: enhanced toxicity in alcoholics. J Clin Gastroenterol 1987;9:180-185.
58. Black M, Raucey J. Acetaminophen, alcohol and cytochrome P450. Ann Intern Med 1986; 104:427-429.

59. Nelson SD. Molecular mechanism of the hepatotoxicity caused by acetaminophen. Semin Liver Dis 1990;10:267-278.

60. Morgan ET, Koop DR, Koon MJ. Comparison of six rabbit liver cytochrome P-450 isozymes in formation of a reactive metabolite of acetaminophen. Biochem Biophys Res Commun 1983;112:813.

61. Watkins PB. Role of cytochrome P450 in drug metabolism and hepatotoxicity. Semin Liver Dis 1990;10:235-250.

62. Lieber CS. Biochemical factors in alcoholic liver disease. Semin Liver Dis 1993;13:136-153.

63. Sato C, Yoshiro M, Lieber CS. Increased hepatotoxicity of acetaminophen after chronic consumption in the rat. Gastroenterology 1981;80:140-1.48.

64. Rubin E, Lieber CS. Hepatic microsomal enzymes in man and rats: induction and inhibition by ethanol. Science $1968 ; 162: 690$ 691.

65. Perot N, Nalpas B, Yang CS, Bedine PH. Modulation of cytochrome $\mathrm{P} 450$ isozymes in human liver by ethanol and drug intake. Eur J Clin Invest 1989; 19:549.

66. Altomare E, Leo MA, Sato C, Vendemiale G, Lieber CS. Interaction of ethanol with acetaminophen metabolism in the baboon. Biochem Pharmacol 1984;33:2207-2212.

67. Girre C, Hippard E, Bolompo S. Increased metabolism of acetaminophen in chronically ill alcoholic patients. Alcohol Clin Exp Res 1993; 17:170-173.

68. Weber CS. Biochemical and molecular basis of alcohol-induced injury to liver and other tissue. N Engl J Med 1988;319:16391650.

69. Peterson FJ, Holloway DE, Erickson RR, Duquette PH, McClain CJ, Haltzman JL. Ethanol induction of acetaminophen toxicity and metabolism. Life Sci 1980;27:1705-1711.

70. Villanueve JP, Roman G, Bruneau J. Pharmacokinetics and metabolism of acetaminophen in normal, alcoholic and cirrhotic subjects. Gastroenterol Clin Biol 1983;65:898-902.

71. Critchley JAJH, Cregeen RJ, Balia-Mood M, Prescott LF, Pentland $\mathrm{B}$. Paracetamol metabolism in heavy drinkers. Br J Clin Pharmacol 1981;13:276P-227P.

72. Prescott LF, Critchley JA. Drug interactions affect analgesic toxicity. Am J Med 1983;75:113-116.

73. Lauterburg BH, Velez ME. Glutathione deficiency in alcoholic: risk factor for paracetamol. HEPATOLOGY 1988;29:1153-1157.

74. Teschke R, Stutuz, G, Strohmeyer G. Increased paracetamol hepatotoxicity after chronic alcoholic consumption. Biochem Biophys Res 1979;91:368-374.

75. Walker RM, McElligott TF, Powers EM, Massey TE, Racz WJ. Increased acetaminophen-induced hepatotoxicity after chronic consumption in mice. Toxicology 1983;28:193-206.

76. Wright N, Prescott FL. Potentiation by previous drug therapy of hepatotoxicity following paracetamol overdosage. Scott Med J 1973; 18:56-58

77. Bray GL, Mowat C, Moir BF. The effect of chronic alcohol intake on prognosis and outcome in paracetamol overdose. Hum Exp Toxicol 1991; 10:435-438.

78. Brotodihardjo AE, Battey RG, Farrell GC, Byth K. Hepatotoxicity from paracetamol self-poisoning in Western Sydney: a continuing challenge. Med J Aust 1992;157:382-383.

79. Sato C, Nako M, Lieber CS. Prevention of acetaminophen-induced hepatotoxicity by acute ethanol administration in the rat J Pharmacol Exp Ther 1981;2218:805-810.

80. Sato C, Lieber CS. Mechanism of the preventive effect of ethanol on acetaminophen-induced hepatotoxicity. J Pharmacol Exp Ther 1981;218:811-815.

81. Banda PW, Quart BD. The effect of mild alcohol consumption on the metabolism of acetaminophen in man. Res Commun Chem Pathol Pharmacol 1982;38:57-70.

82. Altomare E, Leo MA, Sato C, lieber CS, Larrey D. Interaction of acute ethanol administration with acetaminophen metabolism and toxicity in rats fed alcohol chronically. Alcoholism 1984;8:405-408.

83. Lee WM: Acute liver failure. N Engl .J Med 1993;329:1862-1872. 